\title{
Evaluation Of Weight Changes On Wistar Rats Induced By Erythromycin And Aqueous Neem Leaves Extract
}

\author{
Nausheen Adnan, Uzma Bukhari, Iffat Raza \\ $---------------------------------------1$
}

ABSTRACT:

Objective: To evaluate weight changes on the liver of male (albino wistar) rats induced by erythromycin. To assess the outcome of aqueous Neem leaf extract on erythromycin induced hepatic injuries.

Methodology: Eighty male albino wistar rats were taken randomly and were divided into 4 groups of 20 animals each. Group A as a control group. Group B rats were treated with erythromycin drug. Group C rats were treated with erythromycin along with Aqueous Neem leaves extract. Group D were given only Aqueous Neem leaves extract. Body weight of animals was recorded initially and also after experimentation. After 14 days animals were sacrificed, liver weight was also recorded.

Results: The liver of erythromycin treated animals group B were little bigger in size and more reddish. However erythromycin plus Neem treated animals of group C livers were almost like liver of control group A and only Neem given group D animals, liver were exactly same appearance like control group A.Rise in absolute and relative weight of liver was because of drug toxicity.

Conclusion: Its established from this recent study that Aqueous Neem leaves extract being a powerful antioxidant, decreased oxidative stress and hepatic injury caused by erythromycin.

Key Words: Erythromycin, Hepatotoxicity, Azadirachta indica (Neem).

\section{INTRODUCTION:}

Liver is an organ with soft parenchyma ${ }^{1}$. It is extremely vascular, pinkish brown in colour, friable easily with fine and smooth surface. Liver lies in abdomen below diaphragm secured by ribs ${ }^{2}$. The chief role of the liver is detoxification of exogenous and endogenous compounds and therefore its constant exposure to many xenobiotic, pollution, excessive consumption of alcohol, viral infections therapeutic agent's that leads toward compromised condition of liver ${ }^{3}$.

Microscopically each lobe of liver constitute of hepatic lobule. Around the central vein hepatocytic plates are placed in radiating manner within these unevenly hexagonal hepatic lobule ${ }^{4}$. Hepatocytes are organized normally in the form of cords which are one or two cells separated by sinusoids ${ }^{5}$. Sinusoids are the channels that are composed of the hepatocytes plates ${ }^{6}$.

Erythromycin is a commonly used antibiotic belonging to macrolide group of medicinal practice ${ }^{7}$. Erythromycin (EM) is now getting attention because of its unique anti-inflammatory

Nausheen Adnan,
Senior Lecturer, Anatomy Department,
Karachi Institute of Medical Sciences,
CMH Malir Cantt.
Email: Naushinadnan01@gmail.com
Uzma Bukhari,
| Professor, Section Head HistoPathology,
| DIMC,DUHS,Karachi.
I Iffat Raza
Assistant Professor, Anatomy Department,
Karachi Institute of Medical Sciences, CMH Malir Cantt.
Received: 17-09-18
Accepted: 07-12-18 properties. Erythromycin is valuable for the treatment of numerous infections, including tonsillitis, urinary tract infection, bronchopneumonia, mastitis, arthritis ${ }^{8}$. Hepatotoxic osage of Erythromycin stearate $(100 \mathrm{mg} / \mathrm{kg}$ body weight $)$ given orally for 14 days, daily to the rats that initiate liver damage as well as intense hepatotoxicity?

Azadirachta indica (Neem) is considered as a king of therapeutical plant kingdom. Broadly it has been utilized as numerous years prior and still been using for therapeutic and healing purposes. The plant of Neem related to the coastline forests of the tropical region of Sri Lanka, east India and Burma. It is generally predominant in Malaysia, Thailand, Pakistan, Indonesia and Myanmar ${ }^{10}$, it is almost found in nearly about 72 countries ${ }^{11}$. Pharmacological investigations have recognized the estimation of restorative plants as conceivable reason for bioactive compounds ${ }^{12}$.

The best dynamic component is azdirachtin and many other includes nimbin, sodium nimbinate, gedunin, nimbiol, salanin, nimbolinin, nimbidin, and queracetin Neem extract is rich of astringent and salts like fluoride, chloride calcium and sulphur ${ }^{13}$. It contains oils, resin, sterols, flavonoids, silica, gum and alkaloids ${ }^{14}$. It has been established that Neem extract has shown hepatoprotective properties in cases of paracetamol intoxication owing to its antioxidative activity ${ }^{15}$. This study aims to estimate the body weight $\&$ liver weight changes induced through erythromycin on the liver of male (albino wistar rats) and also to assess the outcome of aqueous Neem leaf extract on erythromycin induced hepatic injuries.

\section{METHODOLOGY:}

The research was carried out at the of animal house and the Department of Anatomy, Baqai Medical University Karachi 
.Eighty (80) grown up Albino Wistar male rats of 13-14 weeks of age, weighted between 180 to $200 \mathrm{gms}$ were procured from animal house of BMU. The animals were placed in plastic cages ( 5 animals in each cage) at $30{ }^{\circ} \mathrm{C}$, controlled surroundings with around 14 day and 10 night hours cycle. The rats were given standard feed and water. Acclimatization of animals for about 10 days was assured, prior the start of study. Erythromycin tablets (erythrocin R) $500 \mathrm{mg}$ manufactued by Indus Pharma was purchased from medical store Malir Cantt, Karachi. Aqueous Neem leave Extract was made under supervision of Dr.Sadia senior Scientific Officer at Pakistan Council Scientific \& Industiral Research(PCSIR) Karachi.

The Healthy animals having age of 13-14 week and weighing 180-200 grams were included in the study Only young, active and healthy animals were used for the experiment. Aged, weak and female rats were excluded from the study. Rats died during the study were also excluded. The design of study was experimental study, carried out to observe the outcome of inference.Twenty (20) rats were positioned randomly into four groups; "A", "B", "C" and "D" making it total Eighty (80) male rats. A group was kept as control and received no intervention and was fed with normal diet. Group B Received erythromycin only. Orally $100 \mathrm{mg} / \mathrm{kg}$ body weight as a single dose daily for 14 days through gastric gavage. Group C received erythromycin $100 \mathrm{mg} / \mathrm{kg}$ body weight as a single dose and aqueous Neem Extract of $500 \mathrm{mg} / \mathrm{kg}$ body weight simultaneously through gastric gavage for 14 day. Group D received only aqueous Neem Extract of $500 \mathrm{mg} / \mathrm{kg}$ body weight as a single dose through gastric gavage for 14 days. Neem extract and Erythromycin were given with the help of gastric gavage about 1 hour distinctly.

Before beginning of the study all the animal were weighted on electronic weighing machine and repeated after every 3 rd day. According to group labeled on the cages, rats were kept in separate cages. After final dose animals were weighed for the final weights and then were placed in a glass container where they were given ether anesthesia. The rats were put on dissection board, given midline longitudinal incision, extending from the manubrium sterni until the lower abdomen, in order to expose the organs. After dissecting them, weight of liver was done on electronic scale with the help of following formula, relative weight was calculated ${ }^{16}$. The Relative weight of liver $=$ Liver Weight $(\mathrm{gm}) \times 100$

$$
\text { Final weight of the body (gm) }
$$

Statistical analysis was measured by SPSS (statistical package for social sciences) version 23, complete data was analyzed.Measurable investigation were performed by applying one-way analysis of variance (ANOVA) with the post - hoc Tukeys test taken after by understudy $t$ test. If $P$ value is less than or equivalent to 0.05 , is considered significant with $95 \%$ confidence interval is used for comparison of means among all diverse groups.

\section{RESULTS:}

\section{Body Weight}

Mean value of initial body weight in group "A" were recorded $175.5 \pm 8.78 \mathrm{gm}$ and mean value of final body weight in group A were $185.0 \pm 8.78 \mathrm{gm}$ respectively. It was significantly increased at final stage with mean $185 \pm 8.78 \mathrm{gm}$. Data shown noticeably significant $p$ value $<0.01$

In group $B$ erythromycin treated rats, the mean values of the final body weight of erythromycin treated animals were recorded as $173.3 \pm 13.38 \mathrm{gm}$. Data represents noticeable decrease $(p<0.01)$ in final weight of animal body while compared to initial weight of animals body in group B.

In group $\mathrm{C}$ erythromycin and Neem treated rats, mean values of the initial body weight were recorded, 169.4 $\pm 11.78 \mathrm{gm}$. Final body weights of erythromycin and Neem treated animals of group $\mathrm{C}$, the mean values were recorded $164.1 \pm 11.52 \mathrm{gm}$ respectively. The data presents noteworthy decrease in final body weight $(p<0.01)$ when related to initial body weights of group $\mathrm{C}$ animals.

In positive control group $\mathrm{D}$, mean values of initial body weights were recorded, $176.4 \pm 8.06 \mathrm{gm}$ respectively. Final body weight in group $\mathrm{D}$ animals, mean value were recorded $186.2 \pm 8.12 \mathrm{gm}$. The data indicates significant increase in final body weight $(p<0.01)$ of group $D$ in comparison with to initial body weight of same group.

\section{Absolute Liver Weight}

The absolute liver weight, mean values of control group A were recorded $3.42 \pm 0.25 \mathrm{gm}$.For absolute liver weight mean values in group B (erythromycin treated animals) were $5.38 \pm 0.67 \mathrm{gm}$. Data displays there is noticeable increase in absolute weight of liver $(\mathrm{p}<0.01)$ in group B in comparison with control group A. Mean value of absolute weight of liver in group $\mathrm{C}$ (erythromycin plus Neem treated animals) were $4.76 \pm 0.44 \mathrm{gm}$. According to the data there were significant rise in absolute liver weight $(\mathrm{p}<0.01)$ of group $\mathrm{C}$ animals when compare with control A group animals. The mean value of absolute liver weight in Neem group D animals were $3.41 \pm 0.22 \mathrm{gm}$. The data present no significant change ( $p>0.01)$ in absolute liver weight of group D animals as compare with control group A animals.

\section{Relative Liver Weight}

In control group A animals, mean value of relative weight of liver were $11.3 \pm 6.7 \mathrm{~g}$.In erythromycin treated group B animals, mean value of relative weight of liver were $38.3 \pm 8.6 \mathrm{gm}$. There is a markedly increase $(\mathrm{p}<0.05)$ in the relative liver weight in given data when compared with control group A animals. Mean value of relative weight of liver in erythromycin and Neem treated group $\mathrm{C}$ animals were $33.8 \pm 6.3 \mathrm{gm}$. When comparison with group $\mathrm{C}$ animals to control group A animals there was marked increased 
$(p<0.05)$ in the relative weight of liver. Mean value of relative liver weight in Neem given group D animals were $10.7 \pm 5.9 \mathrm{gm}$. The data represents no significant change ( $p>0.05$ ) of relative weight of group D animals in comparison to relative liver weight of control group A animals

\section{DISCUSSION:}

This study showed that on gross examination in all the four groups, animals liver did not show any noticeable change in size and colour. There were no hemorrhages on the outer surface of the liver.

In this study after 2 week (14 days) of erythromycin treatment, we observed that group B (erythromycin treated) animals were sick as compared to the group A (control animals).

\begin{tabular}{|c|c|c|c|}
\hline Groups & Treatment & $\begin{array}{c}\text { Initial } \\
\text { Weight }(\mathbf{g m}) \\
\text { Mean } \pm \text { SD }\end{array}$ & $\begin{array}{c}\text { Final weight } \\
(\mathbf{g m}) \\
\text { Mean } \pm \text { SD }\end{array}$ \\
\hline A $(\mathrm{n}=20)$ & Control & $175.5 \pm 8.78$ & $185.0 \pm 8.57$ \\
\hline $\mathrm{B}(\mathrm{n}=20)$ & Treated & $184.3 \pm 13.52$ & $173.7 \pm 13.38$ \\
\hline $\mathrm{C}(\mathrm{n}=20)$ & Protected & $169.4 \pm 11.78$ & $164.1 \pm 11.52$ \\
\hline $\mathrm{D}(\mathrm{n}=20)$ & Positive Control & $176.4 \pm 8.06$ & $186.2 \pm 8.12$ \\
\hline
\end{tabular}

Table 1. Mean Body Weight (Gm) Of Rats Of Different Groups At Initial And Final Stage

\begin{tabular}{|l|c|l|}
\hline Groups & Treatment & $\begin{array}{c}\text { Liver } \\
\text { Weight (gm) } \\
\text { Mean } \pm \text { SD }\end{array}$ \\
\hline A $(\mathrm{n}=20)$ & Control & $3.42 \pm 0.25$ \\
\hline B $(\mathrm{n}=20)$ & Treated & $5.38 \pm 0.67$ \\
\hline C $(n=20)$ & Protected & $4.76 \pm 0.44$ \\
\hline $\mathrm{D}(\mathrm{n}=20)$ & Positive Control & $3.41 \pm 0.22$ \\
\hline
\end{tabular}

Table 2. Mean Comparison Of Absolute Liver Weights (Gm) Of Animals

\begin{tabular}{|c|c|c|}
\hline Groups & Treatment & $\begin{array}{c}\text { Relative Liver } \\
\text { Weight(gm), } \\
\text { Mean } \pm \text { SD }\end{array}$ \\
\hline A $(n=20)$ & Control & $11.3 \pm 6.7$ \\
\hline B $(n=20)$ & Treated & $38.3 \pm 8.6$ \\
\hline C $(n=20)$ & Protected & $33.8 \pm 6.3$ \\
\hline D $(n=20)$ & Positive Control & $10.7 \pm 5.9$ \\
\hline
\end{tabular}

Table 3. Mean Comparison Of Relative Liver Weights (Gm) Of Animals. ${ }^{*} \mathrm{p}<0.05$ was obtained using Kruskal wallis test

\begin{tabular}{|l|c|}
\hline Statistical Comparison & Difference (gm) \\
\hline Final weight and initial weight within group A & $-9.5 \pm 2.39$ \\
\hline Final weight and initial weight within group B & $10.6 \pm 1.46$ \\
\hline Final weight and initial weight within group C & $5.2 \pm 0.96$ \\
\hline Final weight and initial weight within group D & $-9.8 \pm 2.0$ \\
\hline
\end{tabular}

Table 4. Statistical Comparison Of Difference In Body Weight Within Same Group *p value $=<0.01$
The animals of group $\mathrm{C}$ appeared to be in better condition as compared to animals of group B.

Group A, animals gained weight when compared with their initial body weight. Whereas, group B (erythromycin treated animals) lost their weight during the period of study. Weight reduction could be due to a disturbed cytochrome P-450 hepatic metabolism.

The same weight changes were observed by $\mathrm{N}$ sambo and Nassr-Allah H, in their work they observed decreased in body weights when erythromycin was given in dose of $100 \mathrm{mg} / \mathrm{kg}$ because erythromycin produces enzyme leakage and other sign of cytotoxicity and disturb the functions of rats liver ${ }^{17,18}$. In opposition to these findings, reported weight gain when using $50 \mathrm{mg} / \mathrm{kg} /$ day erythromycin orally in preterm infants to manage the feeding intolerance in mainly fed milk formula. According to the author erythromycin was successful in assisting enteral feeding in very low birth weight preterm infants with moderate to severe gastric dysmotility ${ }^{19}$. David Amacher observed no changes in body weight in erythromycin treated animals in his work ${ }^{20}$. The animals of group C (erythromycin and aqueous Neem extract treated) lost weight after 14 days but this reduction in weight was much lower than group B (erythromycin treated animals). This is in correspondence with the study concluded by Ajibade Adeshina John, who reported body weight increase in animals after giving aqueous Neem leave extract and paracetamol together in order to observe the hepatoprotective effect of aqueous Neem extract on paracetamol induced hepatic damage.

As Neem leaves contains immunomodulatory, antiinflammatory and adaptogenic activities, it inhibited paracetamol induced lipid peroxidation and protect reduction of sulfhydryl groups in hepatocytes ${ }^{21}$. This is also in agreement to the study by Mohamed A Dhkil. He documented that Neem leaves extract could increase body weight and daily food intake, when given orally about $500 \mathrm{mg} / \mathrm{kg}$ body weight on the rats treated with cisplastin induced hepatotoxicity and oxidative stress in the female rats because of hepatoprotective nature of the Neem leaves. It have noticeable antiperoxidative and antioxidant radical scavenging activities in response to oxidative stress and peroxidative damage ${ }^{22}$.

The body weight of animals of only aqueous Neem leaves extract treated group D, gained weight same as weight gained in animal of group A. This study is simililar with the Oluwole B. Akinola when Azadirachta indica was given at $500 \mathrm{mg} / \mathrm{kg}$ body weight orally in diabetic rats for the treatment of intestinal lesions ${ }^{23}$. Chavan also observed weight gain when Neem leaves extract were used for hepatoprotective activity against Alcohol induced liver injury in rats ${ }^{24}$.

In animals of erythromycin treated group B, the rise in absolute and relative weight of liver was because of drug toxicity. According to Robert R, Maronpot, administration 
of phenobarbital in rats causes hepatotoxicity with raised liver weight due to hyperplasia, enlarged lysosomes, hepatocellular hypertrophy and widening of the hepatic blood space inducing P450 enzymes inducers leads to hepatocellular hypertrophy through smooth endoplasmic reticulum proliferation ${ }^{25}$. This is similar with the study of Xiaoyan $\mathrm{Lu}$, who described the increased in relative weight and absolute liver in animal after administration of erythromycin. According to him, erythromycin induces liver toxicity in both human and experimental animals and it leads to disturbance in energy metabolism, lipid and nucleotide metabolism which may attribute to erythromycin toxicological effect on liver through oxidative stress $^{26}$. In group $C$ animals after the treatment of erythromycin and Neem extract, the absolute and relative liver weight reduced when compare with erythromycin treated group B animals. This is because of less inflammatory changes and less necrosis due to the antioxidant property of Neem leave extract which is accordance to observation of Nassr-Allah $\mathrm{H}$, who observed decreased in animal liver weight with administration of erythromycin and Neem leave extract together ${ }^{18,27}$.

In group D animals which was given only Neem leaves extract the absolute and relative liver weight was not increased when compared to group A rats. This is because of Neem leaves (Azadirachta indica) have antioxidant effect due to it component nimbidin. Similar effect was observed by Raizada who documented, orally administered Neem extract in dose of 500,1000 and $1500 \mathrm{mg} / \mathrm{kg} /$ day did not found any toxicity and changes in absolute and relative liver weights ${ }^{28}$.

In present study, the animals treated only with Neem extract showed ameliorated effect on liver. This is a confirmation of SO innih who reported the activity of Neem extract on liver, the study established that crude extract of aqueous Neem (Azadirachta indica) in considerable amount does not prove any hepatotoxic effect neither any cholestotic effect at 250,500 or $750 \mathrm{mg} / \mathrm{kg}$ body weight doses administered for 28 days $^{29}$. In contrast, Ashafa observed hepatotoxic effect of ethanolic extract of azadirachtica indica stem bark in male Wistar rats in dose dependent manner, however the aqueous Neem extract was not harmful to liver $^{30}$.

The present study evaluates the protective effect of Neem leaves extract on erythromycin induced hepatotoxic effect on rats.

Azadirachta indica have been showing important healthpromoting results because of its immense antioxidant potential. Previous studies have documented that Neem leaves and its compounds has played an important role in the inhibition of disease pathogenesis ${ }^{31}$.

\section{CONCLUSION:}

This recent study determined that erythromycin has hepatotoxic effects on rats. The animals weight changes produced by the erythromycin were finely improved by
Azadirachtiac indica (Neem). Aqueous Neem leave extract is powerful antioxidant because of this it acts as a hepatoprotective agent.

\section{REFERENCES:}

1. Harold Ellis. Anatomy of liver. Journal of surgery 2011;29(12): 589-592.

2. Chummy S, Sinnatam by Regional and Applied Last Anatomy, 2011;12: 238-259.

3. John YL Chiang. Liver Physiology: Metabolism and Detoxification. Pathobiology of Human Disease 2014, pages. 1770-1782, DOI: 10.1016/B978-0-12-386456-7.04202-7

4. Mitra V, Metcalf J. Functional anatomy and blood supply of the Liver. Anaesthesia \& Intensive Care Medicine 2012;13(2):52-53.

5. Michael H. Ross, Wojciech Pawlina MD. Histology; A text and Atlas,6th edition 2015;6:628-658.

6. Poisson J, Lemoinne S, Boulanger C, Durand F, Moreau R, Valla D, Rautou PE. Liver sinusoidal endothelial cells: Physiology and role in liver diseases. Journal of Hepatology 2017;66(1): 212-27.

7. Mohamed M, Abdel-Daim. Pharmacodynamic interaction of Spirulina platensis with erythromycin in Egyptian Baladi bucks (Capra hirus). Journal of research sciences 2014;120(23):234-241.

8. Bosnjakovic A, Manoj K, Ren W, Kurtoglu YE, Shi T. poly (amidoamine) dendrimer -erythromycin conjugates for drug delivery to Macrophages involved in periprosthetic inflammation. Journal of nanomedicine; Nanotechnlogy, Biology and medicine. 2011; (7):

9. Sambo N, Garba SH and Timothy H .Effect of aqueous extract of Psidium Guajava on erythromycin induces Lives Damage in Rats. Nigerian Journal of Physiology sciences. 2009; 24(2): 171-176.

10. Chhibber, S, Sharma, N. Medicinal and therapeutical potential of Neem (azadirachta indica).International Journal of Scientific and Research Publications 2014; 4(5):2250-3153.

11. Girish K, Bhat S. Neem -green treasure .Electronic Journal of Biology 2008; 4930(10); 102-111.

12. Singh V, Chauhan D. Phytochemical evaluation of aqueous and ethanolic extract of neem leaves (Azadiractica indica) Indoamerican journal of pharmaceutical research .2014; 4(12):43-48.

13. Mohammad A .Alzohairay .Therapeutics Role of Azadirachta indica (neem) and their Active constituents in Disease Prevention and treatment. Evidence Based Complementary and Alternative Medicine .2016; 10(7): 1-11.

14. Rao Chava V, Manjunath SM, Rajanikanth AV, Sridevi N. The efficacy of Neem Extract on four Microorganisms Responsible For causing Dental Caries viz Streptococcus mutans,Streptococcus salivarius, Stretococcus mitis and Streptoccocus sanguis. The journal of Contemporary Dental practice 2012; 13(6):769-772.

15. Sunday O. Okoh, Ade O. Oyewole1, Ruth O. Ishola1, Adenike D. Odusote1, Omobola O. Okoh, Chima C. Igwe1 \& Gloria N. Elemo. Antioxidant and Free Radical Scavenging Capacity of Crude and Refined Oil Extracted from Azadirachta indica A. Juss International Journal of Biology 2015;7(2):78-82.

16. Baligar NS, Aladakatti RH, Ahmed M, Hiremath MB. Hepatoprotective activity of neem based constituent 
azadirachtin $-\mathrm{A}$, in carbon tetrachloride intoxicated Wistar rats journal physiol pharmacol 2014; 92(4): 67-77.

17. Nassr-Allah H, Abdel-Hameid .Protective role of dimethyl diphenyl bicarbooxylate (DDB) against erythromycin induced hepatotoxicity in male's rats. Journal of toxicology in vitro 2007; 10: 121-130.

18. Mansi Y, Abdelaziz N. Ezzeldin Z. Ibrahim R .Randomized controlled trial of a high dose of oral erythromycin for the treatment of feeding intolerance in preterm infants. Neonatology. 2011;100(3): 290-294.

19. David E. Amacher, Schomaker SJ, Retsema JA. Comparison of the Effects of the New Azalide Antibiotic, Azithromycin, and Erythromycin Estolate on Rat Liver Cytochrome P-450. Antimicrobial agents and Chemotherapy 1991:35(6):118690.

20. John AA, Bamidele FP and OluwaSeun OA. Some Protective Effects of Aqueous Leaf Extract of Azadirachta indica on Paracetamol-induced Hepatotoxicity in Adult Wistar Rats. American Journal of tropical medicine \& Public Health 2011;1(3): 97-106,

21. Robert R. Maronpot, Yoshizawa K, Nyska A, Harada T, Flake G, Mueller G, Singh B, Ward JM. Hepatic Enzyme Induction: Histopathology. Toxicologic Pathology, 2010;38:776-795.

22. Dkhil MA, Al-Quraishy S, Aref AM, Othman MS, Kamal M. El-Deib and Moneimet AEA. The potential role of azadirchtica Indica treatment on cisplatin induced hepatotoxicity and oxidative stress in female Rats. Oxidative Medicines and cellular longevity. 2013;741817, pages 9. http://dx.doi.org/ $10.1155 / 2013 / 741817$

23. Oluwole B. Akinola, Oluwafunmike S. Akinolaet, Ezekiel A. Intestinal lesions of the streptozotocin-induced diabetes and the effects of Azadirachta indica treatment 2009. Pharmacologyonline 3: pages, 872-881.
24. ChavanT, GhadgeA, KarandikarM, PanditV, RaniekarP, KulkaeniO, KuvalekarA, MantriN. Hepatoprotective Activity of Satwa, an Ayurvedic Formulation, Against Alcohol-induced Liver Injury in Rats Altern Health Med. 2017; 23(4): 34-40.

25. Robert R. Maronpot, Yoshizawa K, Nyska A, Harada T, Flake G, Mueller G, Singh B, Ward JM. Hepatic Enzyme Induction: Histopathology. Toxicologic Pathology, 2010;38:776-795

26. XiaoyanLu, TianY, LianX, Ji, jinT, ZhaoQ, HuB, ShenY, fanX, Integrated system toxicology approaches identified the possible involment of ABC transporters pathway in erythromycin Esolate-induced liver injury in rats. Food and Chemical toxicology 2014;65(6): 343-355

27. Nassr-Allah H, Abdel-Hameid .Protective role of dimethyl diphenyl bicarbooxylate (DDB) against erythromycin induced hepatotoxicity in male's rats. Journal of toxicology in vitro. 2007; 10: 121-130.

28. RB Raizada, M.K. Srivasta, R.A. Kaushal, R.P.Kaushal. Azadiractica indica .A Neem pesticide subchronic toxicity assessment in rats. Food and chemical Toxicology 2001; 39(7): 477-483.

29. Innih, Silvanus Olu, EZE. The effect of Aqueous Extract of Aqueous Neem (Azadirachtica Indica) leaves on liver functions of wistar rats. A Peer-review Journal of Biomedical Sciences. 2014; 13(2):61-66.

30. Ashafa AOT, Orekoya LO, Ykubu MT. Toxicity profile of Ethanolic extract of Azadiractica indica stem bark in male wistar rats. Asian Pacific Journal of tropical Biomedicine 2012; 2(10): 811-817.

31. Ezz-Din D, Gabry MS, Farrag ARH and Moneim AEA. Physilogical and histological impact of azadirachtica indica extract in a rat model of cisplastin induced hepato and nephrotoxicity. Journal of Medicinal Plants Research 2011; 5(23): 5499-5506.

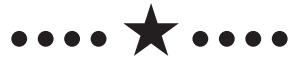

